\title{
A review of current Food Laws and Regálations on addition of nutrients to foods, and their enforcement
}

\author{
M. O.C. de Silva ${ }^{1}$ \\ The Ceylon Journal of Medical Science 1999; 42: 37-41
}

One of the strategies that could be initiated in order to control iron deficiency anaemia is fortification of food with iron. An efficacy trial is presently in progress on the effect of iron fortification of wheat flour. Before such strategies can be recommended for national implementation, it was deemed advisable to inquire into the Laws and Regulations that govern the addition of nutrients to foods, the enforcement procedures to ensure compliance with such Laws and Regulations and the role of the Sri Lanka Standards Institute in such enforcement.

This paper is a summary of a Report on such a study; the full report of the study will be published in a compilation of reports of all studies on the Control of Iron Deficiency Anaemia initiated by the Ministry of Plan Implementation and Parliamentary Affairs.

\section{A review of current Food Laws and Regulations}

The Codex Alimentarius defines food fortification thus: "The addition of one or more essential nutrients to a food, whether or not it is normally contained in the food, for the purpose of preventing or correcting a demonstrated deficiency of one or more nutrients in the population or specific population groups".

\section{Current food fortification practices in Sri Lanka}

Little food fortification is presently being carried out. These include,

i. Enrichment of table margarine with Vitamins $A$ and D, by Ms. Lever Brothers Ltd., the only producer of margarine in Sri Lanka. ii. Enrichment of all salt meant for human consumption, with iodine.

iii. Fortification of bread with vitamins and minerals, by Prima Ltd.

iv. A variety of biscuits fortified with vitamins and minerals.

Programmes $\mathrm{i}$ and ii are mandatory, by law, while the other two are voluntary. The validity of labels on these products have not been investigated by any law enforcement authority. Enforcement is through regular hurry sampling of retail outlets. No records have been kept of the frequency of such checking.

All infant formulae sold in Sri Lanka are imported. It is mandatory that they also be fortified, as in (i) and (ii).

\section{Current Food Laws and Regulations}

The manufacture, importation, distribution and sale of food in Sri Lanka are governed by the Food Act No. 26 of 1980 and Regulations drawn up under the Act.

The Food (Labelling and Miscellaneous) Regulations, 1991, consists of 3 parts:

Part 1. Packaging, Labelling and Advertising of Food

Part 2. General Prohibitions and Regulation of Sales

Part 3. Anti-oxidants and Food Colours

Part 1 details the information that should be displayed on a label, viz. common name, brand 
name, net weight or volume, date of expiry, batch number, name and address of manufacturer or distributor and declaration of the presence of preservatives, artificial sweetners, antioxidants and colouring matter, if any. This part also deals with the labelling of food for which nutrition claims are made. The regulation for nutrition labelling are very scanty: The Codex and the U.S. Federal Regulations also do not specify requirements for nutrition labelling, only providing guidelines for nutrition claims on packages of foods.

Part 2 contains such provisos as foods containing coumarin, aflatoxins and vinyl chloride.

Part 3 deals with the use of antioxidants and colours in foods and the amounts that may be present in the various foods.

There are also 7 other regulations, dealing with preservatives in milk and other foods, iodization of salt, artificial sweetners, importation of food and procedures for sampling of food for analysis.

\section{Food Standards}

Under the present Food Act there are standards laid down for 130 items of food. The Sri Lanka Standards Institution (SLSI) is the only organization empowered by law to formulate food standards. Rarely, a standard is laid down by the Commissioner of Internal Trade on a Cabinet directive, as happened recently in the case of canned fish. The Food Advisory Committee has, infrequently, suggested standards for food products, with the concurrence of the Director General of SLSI, who is a member of the Committee.

The standards promulgated by the SLSI are only voluntary; whenever the need arises the Central government will proclaim that a standard for any product is mandatory. Only then is that standard included in the Food Laws and Regulations.

\section{General principles for fortification of food}

Nutrients may be added to food in order to achieve any of the following objectives:
Restoration of nutrients lost during processing, the nutritional equivalence of substitute foods, and fortification and ensuring the appropriate nutrient composition for a special purpose food.

The salient features of the basic principles, as stated by the Codex Alimentarius Commission are,

1. The essential nutrients should be present at a level that will not result in either an excessive or an insignificant intake of the added nutrient, considering amounts from other sources in the diet.

2. The addition of a nutrient to a food should not result in an adverse effect on the metabolism of other nutrients.

3. The nutrient should be biologically available in the food.

4. The additional cost should be reasonable to the intended consumer.

5. There should be a demonstrated need for increasing the intake of a nutrient in one or more target groups. This may be in the form of actual clinical or sub-clinical evidence of deficiency, estimates indicating low levels of intake of nutrient or possible deficiency likely to develop because of changes taking place in food habits.

6. The food selected as a vehicle for the nutrients should be consumed by the population at risk.

7. The amount of nutrient added to the food should be sufficient to correct or prevent the deficiency when the food is consumed in normal amounts by the population at risk.

Various countries, at various times, have considered or have carried out, fortification/enrichment of food. The food items commonly fortified are wheat flour, rice, sugar, edible oils and fats, common salt and milk powder. 
According to the FAO, 34 countries are listed as being interested in fortification/enrichment of rice. It is not clear as to what commodity the nutrients are to be added, the rice grain or rice flour. The only nutrient that has been considered for addition to rice is iron. Three countries viz. Gautemala, Honduras and El Salvador, fortify sugar with Vitamin A. They are sugar-producing countries and addition of nutrient to sugar is feasible. In Sri Lanka only margarine is fortified with Vitamin A. Addition of iodine to common salt is dealt with comprehensively in the Iodization of Salt Regulations.

Thirty eight countries, according to the FAO, are fortifying wheat flour, the nutrients added being iron, calcium, magnesium, vitamins $\mathrm{B}_{1}, \mathrm{~B}_{2}, \mathrm{~B}_{\psi}$ pantothonic acid and folic acid.

Since iron deficiency anaemia is highly prevalent in Sri Lanka, an efficacy trial is presently being carried out by the Ministry of Plan Implementation and Parliamentary Affairs (M/PI \& PA). Elemental iron has been selected as the fortificant, two forms of which are being used, electrolytic iron and hydrogen reduced iron. At the point of consumption the flour should contain not less than $65 \mathrm{mg}$ iron (as Fe) per $\mathrm{kg}$.

\section{Enforcement procedures}

A significant draw back in the food control system of Sri Lanka is the weak enforcement procedure. The present Food Act No. 26 of 1980 and regulations made thereunder forms a fairly comprehensive piece of legislation which is based on the FAO and the Canadian Food Laws. This legislation is currently being reviewed and revised. The Law is being implemented by the Ministry of Health through its Food Advisory Commit'tee. The actual implementation is through the Director (E \& $\mathrm{OH})$ working under the DDGHS (PHS). The Act is mandatory and its provisions should be enforced throughout the island. Enforcement is through 26 Food Inspectors and a jlarge number of PHIs attached to various local authorities.

With the scanty resources at its disposal the Minis- try of Health carries out a thankless task, which at the best is not good enough. The priority in the Health Ministry is the delivery of good health care. Although provision of safe food is an essential part of the health care service, sufficient attention is still not being paid to food control work. The only local authority doing a fairly satisfactory job is the Colombo Municipal Council.

Food control administration is an important area, and medical professionals are still not alive to its importance. This is the reason why, in countries such as the USA, UK, Australia and New Zealand, such administration is handled by separate organizations outside the Health Ministry.

An important aspect of Food Control is education of food manufacturers, administrators and the consumer. This aspect has not been looked at. A radical change like the separation of food control administration from the Health Ministry may not be possible overnight. Adequate personnel and funding are a sine qua non for the enforcement of Food Laws.

\section{Role of the Sri Lanka Standards Institution in enforcing Food Laws}

The SLSI is the only organization empowered by law to promulgate standards for all consumer goods, including food products. When a product has to be standardized, the officers (Standards Officers) of the Institution draft a set of specifications for the product, after consultation with several knowledgeable persons. The draft is made available to the public for comments and submitted, with such comments, if any, to a Sectoral Committee, consisting of experts in the relevant fields (chemists, food technologists, nutritionists, agriculturists) together with manufacturers, importers and consumers. The final draft is submitted to the SLSI Council for ratification and publication.

Standards thus promulgated are only voluntary. Whenever the need arises the central government will proclaim that a standard for any product is mandatory. 
The composition and standards for Infant Formulae are governed by specifications No. 651 of 1989. This document is in line with the USA as well as the Codex specifications for infant formulae.

The present Sri Lanka Regulations relating to addition of nutrients are:

1. No label or advertisement relating to any food shall indicate thereon that it is an enriched food unless such food contains vitamins, minerals or amino acids in addition to what is naturally contained in such food.

2. No label or advertisement relating to any food shall contain a statement or claim thereon,

i. that such food contains a special nutritional value, unless such label or advertisement bears a declaration thereon stating the nutritional content thereof and quantity of such food recommended for daily consumption, or

ii. that such food is a sufficient source of one or more nutrients, unless the amount of the food consumed in a day contains at least one third of the recommended daily allowance of that nutrient.

iii. that such food contains carbohydrates, proteins, fat, vitamins or minerals, unless such label or advertisement bears thereon a declaration stating the content of such carbohydrates, proteins, fat, vitamins or minerals, as the case may be, per 100 grams of such food, and the quantity of such food recommended for daily consumption and the content of such carbohydrates, proteins, fat, vitamins or minerals, as the case may be, in such quantity of food.

These regulations are scanty. They are in the course of revision.

\section{Recommendations}

The feasibility of fortifying wheat flour with iron is being studied in the Wheat Flour Fortification Trials.

1. The feasibility of fortifying,

a) Wheat flour with Vitamin $B_{1}$ and Vitamin $\mathrm{B}_{2}$

b) Rice flour with iron

c) Margarine with Vitamin D, and

d) Sugar with Vitamin A

will have to be studied by a panel of competent scientists - food scientists, food analysts, nutritionists, microbiologists etc. on the lines of the Wheat Fortification Trials provided that there is a need for this i.e. the prevalence of deficiency diseases due to the lack of these nutrients has been established by the Medical Research Institute.

2. Since Sri Lanka is trying to achieve self sufficiency in rice and to wean the population away from wheat flour, Sri Lanka should seriously start in the direction of fortifying rice flour with iron.

3. It is also recommended that the authorities investigate whether Marie biscuits are enriched/fortified with minerals and vitamins. Whether this is actually done or not the authorities should consider enrichment fortification of this type of biscuits as it is one of the surest ways of getting children to partake of micro nutrients.

4. As stated earlier powdered milk is claimed to be fortified with nutrients by a multinational company. Packeted liquid milk is very popular with school children and working mothers and this is a plus factor for considering enrichment/ fortification of liquid milk.

5. A new clause as "wheat flour shall contain not less than $65 \mathrm{mg} / \mathrm{kg}$ of iron (as $\mathrm{Fe}$ )" be introduced into the existing regulation for wheat flour in the Food (Standards) regulations. 
6. A new regulation such as "no food shall be enriched/fortified with nutrients without the express sanction of the Food Advisory Committee" be introduced into the Food (Miscellaneous) regulations.

7. Even when laws are in place the real problem in Sri Lanka is enforcement. The ideal solution would be an independent Food Authority with its personnel devoted entirely to Food Control Administration. Since this will not be possible soon it is strongly recommended that,

(a) The cadre of Food Inspectors/Public Health Inspectors be increased so that even the smallest local authority will have at least one Food Inspector and one Public Health Inspector on their staff.

(b) More funding and increased transport facilities be made available to the local authorities, and (c) Laboratory capacity i.e. personnel, equipment and chemicals be increased in consultation with the laboratories of the Government Analyst, City Analyst Colombo, City Analyst Kandy and those of the Health Ministry at Kalutara and Anuradhapura.

\section{References}

1. The Progress of Nations 1996 - NUTRITION, UNICEF Internet http./www.uniceforg/pon 96/nufortif htm.

2. Codex Alimentarius Vol. 4 Section 2.

3. Internet/Food Fortification Legislation http.www.fao.org/WAICENT/ FAOINFO/ ECONOMIC/ESN/fortify/regulations.htm

4. U.S. Code of Federal Regulations 1996 Chapter 21. 137-165.

5. The British Bread and Flour Regulations 1998 (SI 141). 